\title{
Factors Influencing Job Satisfaction among Nurses in Public Health Facilities in Mombasa, Kwale and Kilifi Counties, Kenya
}

\author{
Soud Alli Tengah, MSc \\ Faculty of Health \& Life Sciences, \\ School of Psychology. University of Liverpool \\ Ogembo John Otieno (PhD). \\ Dept. of Curriculum, \\ Instruction \& Ed Technology In Kenya, Pwani University
}

\begin{abstract}
The study sought to establish factors that influence job satisfaction of nurses in Kenya. This was necessitated by the need to contribute in bridging existing knowledge gap with regard to predictors of Nurses' job satisfaction. Whereas job satisfaction has been shown to influence nurse retention in employment, turnover rates and provision of quality patient care, job satisfaction of nurses has received minimal attention in Kenya. In Kenya, nurses who constitute the largest cadre of health care providers especially in public health facilities and contribute significantly in the health care system earn low salaries, work in poor working conditions and experience huge nurse to patient imbalance ratio. While these factors among others could have an impact on their morale and ultimately productivity, data on the effect the factors on nurses' job satisfaction is non-existent. This study therefore sought to explore the extent to which demographic factors; perceived leader empowering behaviour; work environment and job stress predict job satisfaction among nurses working in public hospitals within the country. Data was collected using structured questionnaire to 142 nurses in public hospitals in Mombasa, Kwale and Kilifi counties. Findings illustrated that nurses' age, time, work load and reward contribute significantly towards nurses' job satisfaction. other contributing factors were nurse physician relationship and personnel. It is therefore recommended that concerted efforts be put in place to improve the quality of leadership to inspire nurses and thus enhance their job satisfaction, an aspect that is currently missing.
\end{abstract}

Key Words: Job satisfaction, Job stress, Leader empowering behaviour, Work environment.

\section{INTRODUCTION}

Nurses constitute the largest cadre of health care providers who contribute significantly in the health care system in most countries. In Sub-Saharan Africa (SSA), increased turnovers, inadequacy, retention and the perpetual weakening quality of service delivery continue to frustrate nurses making it difficult for the realization of the health indicators in these countries (Asegid, Belachew \& Yiman, 2014; Chan, Tam, Lung, Wong, \& Chau, 2013). While it is important to close the gap of inadequate health care personnel, Freer (2017) cautions about the act of simply increasing the supply of personnel to match the demand and advocates for a robust review of human resource system that would adequately identify the performance gaps, train and promote health care workers' retention, and further sustain the productivity of the workforce. Of particular interest in this regard is nurses' job satisfaction due to its perceived significance in predicting their productivity (Doef, Mbazzi, \& Verhoeven, 2012).

Kenya is among the low middle income countries (LMIC) with meagre resources (Koon, Smith, Ndetei, Mutiso \& Mendenhall, 2016) characterised with low health care personnel; nursing 
staff included which affects attainment of healthcare goals. Like many other countries globally, Kenya recognises that nurses are essential component of the healthcare workforce who are expected to multitask and accomplish varied roles within and outside nursing profession (Abuya, Maina, \& Chuma, 2015). Such according to the researchers include dispensing of drugs as well as taking up doctors' roles. Although considered critical in offering crucial services in the health care system, nurses in Kenya operate under the imbalance ratio of 8.3:10,000 as opposed to the WHO recommended 25:10,000 (Okeyo, 2017; Utriainen \& Kynga, 2009). Additionally, they earn low salaries and have limited career development opportunities. Cumulatively, the prevailing conditions pose a threat of attrition and job dissatisfaction among nurses within the country. As a matter of fact, these concerns have precipitated bitter disputes between representative of nurses such as National Nurses Association of Kenya and Kenya National Union of Nurses with both the central and county government (Onsarigo, 2014; Wahito, 2013). Of concern to representatives have been calls for improving nurses' job conditions including compensation (Kimanthi \& Nyamai, 2017). With the disputes culminating into country wide strikes that often paralysed the entire health care system for months on end (Kimanthi \& Nyamai, 2017), it has been speculated that nurses job satisfaction could be at the lowest. However, empirical data that could specifically illustrate the extent to which such factors could have impacted nurses' job satisfaction are non-existent. As a matter of fact Tarcan, Hikmet, Schooley, Top, and Tarcan (2017) laments about the lack of empirical data specific to developing countries such as Kenya despite the existence of several studies carried out on job satisfaction among nurses globally. The study thus sought to establish the factors influencing job satisfaction among nurses in public hospitals in Kenya with a specific focus on nurses working in health facilities in Mombasa, Kwale and Kilifi counties.

\section{Demographics}

Studies conducted across the globe have indicated women to be the majority among the nursing profession (Milutinovic', Golubovic', Brkic' \& Prokes², 2012). Those carried out in the Nordic countries namely Sweden, Norway and Finland found out that only 6\% of the respondents were men, the rest being women (Lindqvist et al., 2014). In Ghana, studies carried out in public hospitals identified female nurses to be the majority (83.7\%) compared to male $(16.3 \%)$ (Sanda \& Cudjoe, 2018). Despite the feminine predominance, this was not significantly related to job satisfaction compared to their male nurses who showed to be more satisfied than women (Asegid et al., 2014) in addition men were found to be more satisfied in relation to their stability in employment (García, Solano-Ruíz, Martínez-Roche \& Gómez-García, 2013 ). Similar findings were also established in Northern Greece army hospital where male nurses were found to be highly satisfied (Malliarou, Sarafis, Moustaka, Kouvela, \& Constantinidis, 2010). However there were also contradictory findings that showed women to be more satisfied than men (Herrera \& Manrique, 2008; Ramírez \& Lee 2011). In an attempt to explain the variation, Malaysian male nurses were found to be less satisfied as they considered themselves underpaid while the female counterparts perceived themselves as satisfied since they were able to contribute meaningful into their household income which gave them sense of satisfaction (Atefi, et al. 2014). Findings by García et al. as cited by Clark (2013) indicated that women may attach lower expectations onto their jobs hence easily satisfied compared to men who set their expectations so high making it difficult to realise all of them.

Regarding age, there has been varying significant differences in literature with relation to job satisfaction and age. There are studies that show job satisfaction to decrease with increase in age (Tapia, Ramírez, Islas, 2009), while others indicate that job satisfaction increases with increase in age (Curtis \& Glacken, 2014; Li \& Lambert 2008). Others claim that no relationship exists between age and job satisfaction (Bhandari, Xiao \& Belan, 2015). These findings therefore indicate that there is no unanimity on the perception of job satisfaction among 
nurses due to conflicting results in varying studies. Married nursing staffs were found to have less job satisfaction according to a study carried out in India that attributed the low job satisfaction to their pressurised family environment characterised by burden of the household work which might contribute to insomnia and depression (Viswam, Valsaraj \& Jose, 2013). Inferring that nurses who are single have higher job satisfaction might not be a correct experience considering existence of conflicting studies (Kumar et al, 2013). Nurses who had lower level of education such as at diploma level were reported in Ethiopian study to experience high level of job satisfaction compared to the ones possessing nursing degree (Semachew, Belachew, Tesfaye, \& Adinew, 2017). Such findings are consistent to studies carried out in USA (Kalisch, Lee \& Rochman, 2010) and Kuwait (Al-enezi, Chowdhury, Shah, \& Al-otabi, 2009) indicating high level of education to be correlated with low level of job satisfaction.

\section{Perceived Leader Empowering Behaviour}

Studies indicate that in most Sub-Saharan Africa, there is extreme shortage, poor capacity and de-motivated nurses (Crisp \& Chen, 2014). The situation according to the researchers is made worse by the emigration of these health care providers to Europe and America which not only affect the existing personnel retention but also compromises the quality of service rendered to patients. It is therefore imperative to focus on improving the full potential of the few remaining nurse's, a task in which leader empowering behavior is said to play a crucial role. Studies have revealed that leaders have immense influence on their employee performance, work environment and job satisfaction hence it is conceivable to believe that nurse manager leadership style contribute immensely on the nurses organizational performance, quality of service to the patient and job satisfaction of the employee (Deriba et al, 2017). According to the researchers, leader empowering behaviour was found to be linked to psychological empowerment and therefore positively associated with job satisfaction. Consequently, a focus on the perception of the nurses and their nurse manager empowering behavior is an essential component in addressing nurse attitude, performance and job satisfaction (Elsetouhi, Hammad, Nagm, \& Elbaz, 2017). The focus on the leadership style of nurse manager therefore is a logical and important process to ensure nurses' job satisfaction is realized.

Previous studies indicate that efficient leadership styles and quality leadership skills by the nurse manager contributes significantly in promoting excellent patient care, job satisfaction and retention of nurses (Henriques, 2015). Even though literature documents a number of theories of leadership, very few of these theories have a relationship with the Herzberg two factor theory and job satisfaction. This study sought to explore the link between two types of leadership styles namely transactional and transformational leadership which have been extensively applied in health care set up (Morsiani, Bagnasco, \& Sasso, 2016).

\section{Transactional Leadership and Transformational Leadership}

Transactional leadership (TAL) borrow a lot from the traditional type of manager who identifies objectives, controls and manages resources, information and data, and monitor performance. TAL is characterized by the desire to maintain the traditional organizational culture, policies and procedures (Abualrub \& Alghamdimg, 2012). Key components in TAL include contingent rewards which involves provision of physical reward like financial or fringe benefits including verbal recognition of the staff performance mimic extrinsic factors in the Herzberg two factor theory; active management by exception where the leader deliberately establish faults in the work of the supervisee; passive management of the leader in supervisee work and only presence in an event of faults and lack of involvement of the manager in subordinate work affair (Top, Tarcan, Tekingündüz, \& Hikmet, 2013). On the contrary, transformational leadership (TFL) inspires followers and is characterized by a visionary, close 
supervisory contact relationship between the supervisor and supervisee and poses charismatic qualities of leadership (Braun, Peus, Weisweiler, \& Frey, 2013). Doody \& Doody (2012) described the four behavioural components that leaders apply in accomplishing TFL namely; idealized influence on his followers, individual consideration on staff growth and needs, intellectual stimulation on new ways of doing things and inspirational motivation.

A conducted in Northern Italy examining job satisfaction of nurses based on their perception of nurse managers leadership style revealed that nurse manager who used TFL had a high positive correlation with JS of the nurses, indicating that TFL positively influence the nurses JS (Morsiani et al., 2016). Similar findings were also observed in studies conducted in hospitals where nurse managers adopted TFL style (Casida \& Parker, 2011; Abdelhafiz et al., 2015). In addition American Nurse Association (2013) reported two top most factors that enhance satisfaction of the nurses to be involvement in decision making and feeling of being respected by their nurse manager. Morsiani et al., (2016) reported that TAL style of leadership had the lowest correlation with nursing staff satisfaction. Conversely, in a study carried out in Jordan to explore how leadership style of nurse leaders affect job satisfaction among nurses working in government and private hospitals, findings revealed that TAL had a stronger relationship with JS compared to TFL (Abdelhafiz et al., 2015). The realization of the stronger relationship was mainly influenced by the contingent reward style of leadership where nurse manager rewarded meaningfully nurses based on task completion (Abdelhafiz et al., 2015). Studies have also illustrated that hospital with strong financial reward system tend to have improved job satisfaction among nurses and better job outcomes (El Amouri, 2010). Thus, it is important to note that despite TFL being highly regarded as better leadership style, efficient application of the leadership skills in motivating staffs towards achieving the shared vision is critical (Casida \& Parker, 2011).

\section{Job Stress}

Cognitive theorists have identified job stress to be as a result of the interaction between employee and work environment which eventually affect the performance of the staff (Jou, Kuo, \& Tang, 2013). Nurses being front-line health care providers, experience various work related stress such as long working hours, unpredictable reactions from patients and their relatives as well as emotional relationships resulting into emotional exhaustion (Happell, Dwyer, Reid-Searl, Burke, Caperchione, Gaskin, 2013). Others include death of a patient and fear of contracting communicable diseases, leading to burnout (Hayes, 0"Brien-Pallas, Duffield, et al, 2012) physical illness, depression, (Lin, Probst, Hsu, 2010), organization culture, interpersonal relationships and work related demand (Chung, Jung \& Sohn, 2017) and diminished mental health,( Hamdan-Mansour, Al-Gamal, Puskar, Yacoub, Marini, 2011). This observation is also supported by Chung, Jung \& Sohn (2017). The study thus sought to review the contributions of work load, nurse managerial support and organizational on nurses' job stress.

Workloads, long working hours and unsatisfactory compensation were found to be key drivers of job stress in Africa (Makola, Mashegoane \& Debusho, 2015) and especially among nurses (Shihundla, Lebese \& Maputle, 2016). They were found to threaten nurses job satisfaction (Oldenburg, 2016). Workload in the nursing profession has also been used as a parameter to assess the staffing composition as either oversized, understaff in order to avoid dissatisfaction and burnout among nurses (Mera et al., 2009). With regards to relationship, Sanda and Cudjoe, (2018) established a highly significant negative correlation between workload and job satisfaction among nurses working in public hospitals in Ghana. This finding is also consistent with that of Lindqvist et al., (2017) in a Nordic study which observed that workload among nurses was negatively correlated with job satisfaction and greatly influence the intention to 
leave the profession (Lindqvist, Alenius, Runesdotter, Ensio, Jylhä, Kinnunen, Sjetne, Tvedt, Tjønnfjord \& Tishelman, 2014). Hence effective management of the staff workload could possible translate to job satisfaction.

Reward has been considered to be a strong predictor of job satisfaction and inadequacy or lack of it. It was found to cause dissatisfaction and negatively affect nurses performance (Seitovirta, Vehviläinen-Julkunen, Mitronen, De Gieter \& Kvist, 2016). Moreover studies noted that reward if not properly communicated and executed is bound to promote negative feelings among nurses such as grudges about inequality. Caution should also be taken into consideration when executing both the intrinsic (recognition) and extrinsic factors (monetary reward) as it has been observed that in low job satisfaction reward situations, employees might not necessarily resign but become unhappy with their job hence affect the quality of service and endangers the life of the patient as well as create organizational risks (Hsu, et al., 2015). Although Hsu, et al., (2015) explicitly focused on monetary rewards, Morgan and Lynn (2009) as well as Adriaenssens, De Gucht, van der Doef, \& Maes, (2011) argues that solitary focus on monetary reward is unlikely sufficient to retain nurses to continuously offer patient care. They recommend a fair and holistic reward system which would promote and sustain job satisfaction, retention and commitment of the nurses. Von Bonsdorff, (2011) also found that employee feeling of being appreciated and recognized increased job satisfaction of nurses. Other proponents of this school of thought include Danish and Usman (2010), Islam and Ismail (2008) as well as Klopper, Coetzee, Pretorius Bester, (2012).

The managerial support (MS) offered by the nurse manager offer is influenced by the quality of the workplace relationship that exist between nurses and nurse manager as alluded in the Social Exchange Theory (Brunetto, Xerri, Farr-Wharton, Shacklock, Farrwharton \& Trinchero, 2016). The MS can either be instrumental which involves provision of job related information and feedback or provision of emotional support comprising empathy, caring, comfort and encouragement (Reblin \& Uchino, 2008). It requires a lot of effort both intrinsic motivation and extrinsic motivational strength for one to be able to provide optimum supervisory support to the employees (Folbre, 2012). Employee who received managerial emotional support have been known to be highly stable in discharging their tasks and more satisfied (Xanthopoulou, Bakker, Demerouti, \& Schaufeli, 2009). Also experience high levels of congruence between their goals and their capabilities, while those who lack it are greatly withdrawn from their work and affects their performance (Xanthopoulou et al, 2009). Moreover, nurse MS have been found to reduce emotional exhaustion and negative attitudes among nurses (Reblin \& Uchino, 2008). Nurses may perceived their managerial as supportive based on how they help them during times of need, being praised for job well done, values their contribution and the care for their wellbeing (Edmondson \& Boyer, 2013), feel more competent and valued (Pohl, Dal Santo, \& Battistelli, 2013). Such perceptions impact on their organization performance, JS and staff turnover (Brunetto et al., 2016). Meta-analytical review of Edmondson and Boyer (2013) concluded existing of a significant positive correlation between MS and JS (Day, Crown \& Ivany, 2017) effect on turnover and quality of patient care (Smollan, 2015). Similar findings were also observed in various studies that managerial support is a strong determinant of JS (Galletta, Portoghese, Penna, Battistelli, \& Saiani, 2011).

Employee job stress has also been linked with their job satisfaction. For instance, in a study conducted in Southwest China, moderate but significant negative correlation was established between job stress and job satisfaction among the community health nurses (Shihundla et al., 2016) indicating the need for the nurse managers to develop strategies to manage employees work place level in order to improve their job satisfaction. Pignata, Boyd, Gillespie, Provis \& Winefield (2014) in their study of Australian university employees found out that employee 
who received a stress reduction management were significantly satisfied in their jobs compared to those who did not receive the treatment. This means that job stress negatively influences job satisfaction. Similar findings were also observed in studies carried out in United States by Liu and Ramsey (2008) and Von der Embse, Sandilos, Pendergast, \& Mankin (2016). In the same vein, findings show that stress due to work contributes in diminishing JS (Delobelle, Rawlinson, Ntuli, Malatsi, Decock, \& Depoorter, 2011). Doef et al., (2012) in their cross sectional study of female nurses carried out in Kenya, Tanzania and Uganda also found that job stress negatively affected job satisfaction. On the contrary, Gandhi, Sangeetha, Ahmed \& Chaturvedi (2014) identified a significant positive correlation between job stress and JS in a cross-sectional study of 150 psychiatric nurses in Bangalore India, The psychiatric nurses exhibited very high levels of stress (95\%) and also showed higher levels of job satisfaction $(82 \%)$ which was thought to be attributed to 'higher financial benefits' in Indian public hospitals. However a negative correlation of $16 \%$ was also recorded between perception of job stress and satisfaction.

\section{Work Environment}

Nursing shortage is a worrying phenomenon that has been classified as an international concern (Johnson et al., 2016) characterized by psychological and physical negative health consequences (Bernal et al., 2015). Conducive nursing work environment has been identified as one of the essential component that might provide a solution to the nursing psychological and physical effect through improving nurses JS and which in return influence reduction in staffing turnover (Al-Kandari \& Thomas, 2008). As cited by Kramer and Schmalenberg of magnet hospitals in Ganz and Toren (2014), work environment that is perceived by the nurses as attractive is considered highly in attracting and retaining nurses as well as associated with increased JS while inadequate working environment has been found to increase nurse turnover and associated with a lack of JS. Studies carried out in developed countries found out that positive perceptions of the work environment enhanced nurse's job satisfaction (Ganz \& Toren, 2014; Zhang et al., 2014; Rochefort \& Clarke, 2010). These findings are consistent with studies from South Africa, Nigeria and Uganda in Sub Saharan Africa (Delobelle, et al, 2011). Also in line with Doef et al., (2012) in their study of East African nurses that job satisfaction is correlated with improved working conditions such as staffing, workload and availability of equipment. In line with study theoretical framework, that identified work environment as an essential component in nursing satisfaction (Raziq and Maulabakhsh, 2015). Work environment form part of the identified hygiene factors (working conditions) which are known not to cause satisfaction according to Herzberg theory but can change dissatisfaction into no dissatisfaction, a phenomenon that has been argued by Baah and Amoako (2011) that hygiene factors are equally important factors that once are well taken cared they not influence job dissatisfaction but also job satisfaction.

Physicians and nurses relationship has been identified as one of the key components in the five segments of the effective nursing work environment (Ganz \& Toren, 2014). Boyle \& Kochinda as cited in Galleta, Portoghese, Carta, D'Aloja and Campagna (2016) defined working relationship as an interaction between staff member who work together towards solving a common medical conditions. Nurses and physicians perform various functions together from triage, conducting diagnostic tests, patient admission, administering treatment, care and support among other interventions with the aim of improving the patient outcome (Galleta, et al., 2016). During the process of carrying out these duties, communication and coordination among nurse-physician is quite crucial (Livorsi et al.2016). Insufficient relationship and communication between nurses and physicians have been found to significantly contribute to medical errors, reduce job satisfaction, undesirable patient outcomes, increase turnover or absenteeism (Dougherty, 2009; Boev \& Xia 2015). While on the other hand positive 
relationship enhances nurse-physician relationship and strengthening bonding which promote quality patient care, prevent confrontations and promote nurses job satisfaction and patient outcomes (Karamano_glu, Ozer, \& Tu_gcu, 2009). Similar findings of positive correlation with JS were observed in a cross sectional study carried out in Beijing between nurse-physician (Zhang et al. 2016). Chandrasekar (2011) argue that for organizations to ensure quality work environment is maintained, human to human interactions and relations play a significant role in attaining job satisfaction. Traditionally it has been perceived that nurses need to take a subordinate role and implement the orders while the physician dominate the decision making (Lancaster, Kolakowsky-Hayner, Kovacich, \& Greer-Williams, 2015). But with progressive development in the nursing and healthcare, professional nurses are now gaining independent recognition role and expect more power in the relationship and decision making (Varjus, Leino-Kilpi, \& Suominen, 2011; Chen et al., 2015). Therefore it is important for the nurse managers to support the mutual nurse physician relationship and strive to ensure optimal outcome on the relationship is realized.

Inadequate nursing personnel has been considered as a key component of poor supportive work environment (Lu, Ruan, Xing, \& $\mathrm{Hu}, 2015$ ), which is associated with higher job dissatisfaction (Nantsupawat, Nantsupawat, Kulnaviktikul, \& McHugh, 2015). Several measures have been employed in measuring nursing personnel such as number of nursing care hours per patient or bed capacity care, nurse to patient ratio and also the subjective measure of using nurses perception in determining the adequacy of the nurse in offer quality patient care (Aiken et al., 2011; Kalisch, Tschannen \& Lee, 2012; Staggs, Knight, \& Dunton, 2012). The nursing patient ratio in most of the settings especially in the SSA is below the WHO recommended ratio of 25:10,000, like in Kenya a great imbalance of the nurse-patient ratio is experienced of 8.3:10,000 (Utriainen \& Kynga, 2009; Okeyo, 2017) which is associated with increased burnout and lower job satisfaction (Aiken, Clarke, Sloane, Lake, \& Cheney, 2008; Nantsupawat et al., 2015). In the meta-analysis conducted by Shin, Park, \& Bae, (2018) it found that the nursing personnel levels are crucial components in the health care delivery and imbalance is related to higher level of burnout and lower level of job satisfaction, similar findings were observed by Kane, Shamliyan, Mueller, Duval, \& Wilt, (2007) which found that increased nursing personnel to be associated with improved patient outcome and lower mortality rates contributing improved job satisfaction leading to staff retention. Additionally in the same vein correlating between perceptions of adequate personnel and job satisfaction has been identified (Anderson et al., 2009; Rochefort \& Clarke, 2010; Kalisch et al., 2011). However contrary findings were also observed in a study of nurses conducted in Finland that nursing personnel levels is not related to job satisfaction (Tervo-Heikkinen, Kiviniemi, Partanen, \& Vehviläinen-Julkunen, 2009). The study was based on four objectives:

1. To explore the relationship that demographic factors such as age, gender, marital status and education have on job satisfaction of nurses.

2. To establish the extent to which perceived leader empowering behaviours contributes to job satisfaction of nurses

3. To examine the impact job stress has on job satisfaction of nurses.

4. To examine how work environment contributes to the job satisfaction of nurses.

\section{Design}

\section{METHODOLOGY}

The study is quantitative in nature to allow examining the prediction of factors that influence the relationship between an independent variable and the dependent variable (nurse's job satisfaction). A structured survey design was adopted in which nurses working in public hospitals were provided with anonymous questionnaire to share their work experiences. The questionnaire sought to understand nurses' experience on perceived leader empowering 
behaviour, job stress, work environment and job satisfaction. It was adopted from existing literature including leader empowering behaviour scale, Minnesota satisfaction questionnaire and Effort reward imbalance. It was localised to fit the Kenyan context and contained a five point Likert scale. In view of the adaption, piloting of the instrument was carried out to assess validity and reliability. The reliability of the questionnaire items were as presented in Table 1.

Table 1 Reliability Index

\begin{tabular}{lcc}
\hline Variable & No. of items & Cronbach Alpha \\
\hline Perceived leader empowerment behaviour & 7 & 0.82 \\
Job stress & 7 & 0.68 \\
Work environment & 7 & 0.80 \\
Job satisfaction & 5 & 0.70 \\
\hline
\end{tabular}

Findings show that the questionnaire items for perceived leader empowerment behaviour, work environment and job satisfaction yielded a reliability index of more than 0.70 while that of job stress was slightly less than 0.70. Specifically, elements of perceived leader empowerment behaviour attained the highest reliability index of 0.82 , followed by elements of work environment $(0.80)$ then job satisfaction $(0.70)$ and lastly job stress $(0.68)$. The reliability index of the variables was deemed high enough according to Kothari (2004) to allow for their use.

\section{Participants}

The study was conducted among nurses in three hospitals namely Coast Provincial General Hospital, Kilifi County Hospital and Msambweni Hospital. The study sites were selected based on demographic characteristics that these facilities hold including representation of Coastal population especially the nursing community. Hence their experiences and findings could be representative of the remaining coastal areas. Out of the 550 nurses working in various units including out-patient, surgical ward, intensive care unit, theatre, neonatal, comprehensive care centers, pediatric clinics and ward, general ward, private wards, emergency and casualty, participants 148 were sampled with precision level $\pm 7 \%$, confidence level $95 \%$ and $\mathrm{P}$ value 0.5 . Table 2 provides a summary of study sample.

Table 2 Sample Size

\begin{tabular}{lccc}
\hline Name of the hospital & Percentage & Strata population & Strata sample size \\
\hline Coast Provincial General Hospital & $65 \%$ & 358 & 96 \\
Msambweni Hospital & $15 \%$ & 82 & 22 \\
Kilifi County Hospital & $20 \%$ & 110 & 30 \\
Total & $\mathbf{1 0 0 \%}$ & $\mathbf{4 5 0}$ & $\mathbf{1 4 8}$ \\
\hline
\end{tabular}

\section{Data collection procedure}

Approval was obtained from the University ethical review committee and at the $\mathrm{CPGH}, \mathrm{KCH}$ and $\mathrm{MH}$. The process for getting the approval involved application for ethical review and addressing the issues raised by the committees, doing oral presentation to the hospital management team, county department of health in the three countries of Mombasa, Kilifi and Kwale. Thereafter, participants were engaged in small groups ranging from 3, 5 or 7 or even at individual level to explain the objective of the study and also take them through the consent form prior to their participation. Subsequently, questionnaire was distributed to the participants and collecting box availed within the nursing department where individual nurses would drop the forms anonymously to be picked latter. Due to the nature of nurses job in attending to patient's needs, adequate time was allowed to elapse before filled questionnaire were collected. 


\section{Measures}

Leader empowering behaviour. Seven items measured leader empowering behaviour which was sub-divided into two subscales; transactional and transformational leadership. Transactional leadership was the extent to which nurses perceived their nurse manager desire to maintain the traditional organizational culture, policies and procedures (Abualrub \& Alghamdimg, 2012). Transformational leadership was a measure of the extent to which nurses perceived their nurse manager to be either visionary or offer close supervisory support and possess charismatic qualities of leadership that influence followers (Braun, Peus, Weisweiler, \& Frey, 2013; van Knippenberg \& Sitkin, 2013). The ratings were made on a 5-point scale. Mean scores were computed for each of the subscale.

Job stress. Seven items measured the extent to which nurses perceived job stress due to their work. Elements of the variable were sub-divided into work load, reward and managerial support sub-scales. Work load was the extent to which nurses' perceived staffing composition at their workplace to influence their job satisfaction (Mera et al., 2009). Reward was the extent to which nurses' feeling about compensation influenced their job satisfaction (Flinkman, Isopahkala-Bouret \& Salantera, 2013). Managerial support was the extent to which the nurses perceived provision of job related information and feedback as well as emotional support from their nurse manager to influence their job satisfaction (Reblin \& Uchino, 2008). The ratings were made on a 5-point scale and a mean score computed for the items.

Work environment. Seven items measured nurses' perception of the influence of their work environment on their job satisfaction. Elements of the variable were sub-divided into collaboration, personnel and equipment sub-scales. Relationship was the extent to which nurses perceived their nurse-physician collaborative practices influenced their job satisfaction (Rosenstein et al., 2002 as cited in Zhang, Huang, Liu, Yan \& Li, 2016). Mean scores of the items were computed.

\section{DATA ANALYSIS}

The data was analysed descriptively and inferentially with the aid of Statistical Package for Social Science (SPSS) version 23. Descriptive techniques including frequency, percentage, mean and standard deviation were used to explain the distribution of the variables while inferentially, logistic regression aided in determining relationships between the independent and dependent variable. Research hypotheses was tested at $\alpha=0.05$.

\section{Ethical considerations}

An ethical review process was undertaken both by University of Liverpool Review Committee and locally in Kenya by the ethical review committee at Pwani University and Coast Provincial General Hospital, each authorizing the study. Authorization of data collection was also sought at County Department of Health for Mombasa, Kilifi and Kwale and the hospital management teams respectively. Lastly, informed consent was obtained from each participant. They were informed of the study objectives verbally and in written form through participant's advertisement. On accepting to participate in the study, they were requested to sign a consent form. Anonymity and confidentiality of participants was assured and adhered to.

\section{Demographic Data}

\section{RESULTS}

Data was collected from 142 nurses, a majority, 83.1\% $(n=118)$ being females while only $16.9 \%$ were males. With regard to age, a significant proportion, $42.3 \%(n=60)$ were below 35 years old, $27.5 \%$ in 35-44 age bracket, $24.6 \%$ were $45-54$ years old while $5.6 \%$ were 55 years old and above. At the same time, findings established that most of the nurses were married 
(71.1\%) with only $28.2 \%$ being single and $0.7 \%(n=1)$ was divorced. Lastly, a significant proportion, $85.9 \%$ were employed on permanent terms, $76.8 \%(n=109)$ had diploma in nursing while $9.2 \%$ had a certificate and $13.3 \%$ degree in nursing. Data obtained illustrated that a significant majority of the nurses (71.8\%) had low levels of job satisfaction though slightly more than a quarter had high levels of job satisfaction. Table 1 present a summary of this information.

Table 3 Nurses level of job satisfaction

\begin{tabular}{lcc}
\hline Level & Frequency & Percentage \\
\hline Low & 102 & 71.8 \\
High & 40 & 28.2 \\
Total & $\mathbf{1 4 2}$ & $\mathbf{1 0 0 . 0}$ \\
\hline
\end{tabular}

\section{Demographic factors and job satisfaction of nurses}

Logistics regression was used to determine the relationship between demographic factors of nurses and their job satisfaction. The findings were as shown in Table 4.

Table 4 Relationship between nurses' demographic characteristics and their job satisfaction

\begin{tabular}{llcccccc}
\hline & & B & S.E. & Wald & df & Sig. & Exp(B) \\
\hline Step 1 ${ }^{\mathrm{a}}$ & Gender & -.178 & .509 & .122 & 1 & .727 & .837 \\
& Age & -.428 & .218 & 3.865 & 1 & .049 & .652 \\
& Marital status & .532 & .383 & 1.929 & 1 & .165 & 1.703 \\
L/Education & -.167 & .331 & .256 & 1 & .613 & .846 \\
E/status & .221 & .404 & .299 & 1 & .585 & 1.247 \\
Constant & -.391 & 1.627 & .058 & 1 & .810 & .676 \\
\hline
\end{tabular}

a. Variable(s) entered on step 1: Gender, Age, Marital status, L/Education, E/status.

The independent variables in the model were gender, age, marital status, level of education and employment status. The model was significant, $\chi^{2}(4)=25.18, p<0.001$ and the Hosmer and Lemeshow Test confirmed model fit, $\chi^{2}(8)=9.713, p=0.286$. Cox \& Snell R Square predicted a variance of $6.5 \%$ while Nagelkerke $\mathrm{R}$ Square predicted $9.3 \%$ in variation in job satisfaction explained by the model. The model with independent variables explained $74.6 \%$ of nurses' job satisfaction due to demographic factors, an improvement from the $71.8 \%$ initially predicted. Nurses marital status predicted their job satisfaction, Wald $\chi^{2}(1)=1.93, p=0.165, \operatorname{Exp}(B)=$ 1.703) the observation being insignificant while it dropped by 0.84 due to gender. Similarly, the odd of nurses' job satisfaction dropped by 0.65 and 0.85 due to their age and level of education, the odds due to age being significant. Nurses who were below 35 years reported being highly satisfied compared to those who were 35-44 years, or 45-54 and 55 and above. Lastly, though insignificant, employment status increased the odds of nurses' job satisfaction by 1.247 , Wald $\left.\chi^{2}(1)=0.300, p=0.585, \operatorname{Exp}(B)=1.247\right)$.

\section{Perceived leader empowering behaviour and job satisfaction of nurses}

The study sought to establish the extent to which perceived leader empowering behaviour predicted nurses' job satisfaction. Descriptive findings showed that the contribution of transformational leadership traits on job satisfaction of nurses was higher $(\mathrm{M}=14.39, \mathrm{SD}=$ 3.78) as compared to the contribution of transactional leadership ( $\mathrm{M}=9.51, \mathrm{SD}=2.58$ ). Logistic regression was used to illustrate the subscale that best predicts the extent to which each of the leader empowering behaviour (LEB) contributed to nurses' job satisfaction. Table 5 presents the findings. 
Tengah, S. A., \& Otieno, O. J. (2019). Factors Influencing Job Satisfaction among Nurses in Public Health Facilities in Mombasa, Kwale and Kilifi Counties, Kenva. Advances in Social Sciences Research Journal, 6(5) 128-144.

Table 5 Logistic regression results predicting nurses job satisfaction due to LEB

\begin{tabular}{lcccccc}
\hline & B & SE & Wald's $\boldsymbol{\chi}^{\mathbf{2}}$ & df & Sig. & Exp(B) \\
\hline Transformational & .114 & .072 & 2.496 & 1 & .114 & 1.121 \\
Transactional & .105 & .097 & 1.166 & 1 & .280 & 1.110 \\
Constant & -3.689 & .975 & 14.326 & 1 & .000 & .025 \\
\hline
\end{tabular}

a. Variable(s) entered on step 1: Transformational, Transactional

The independent variables in the model were transformational and transactional leadership traits. The model was significant, $\chi^{2}(4)=26.08, p<0.001$ and the Hosmer and Lemeshow Test confirmed model fit, $\chi^{2}(8)=2.24, p=0.973$. Cox \& Snell R Square predicted a variance of $6.7 \%$ while Nagelkerke R Square predicted $9.6 \%$ in variation in job satisfaction explained by the model. The model with independent variables explained $70.9 \%$ of nurses' job satisfaction, a decrease from the $72.3 \%$ initially predicted. Transactional leadership predicted nurses job satisfaction, Wald $\left.\chi^{2}(1)=2.50, p=0.114, \operatorname{Exp}(B)=1.121\right)$ the observation being insignificant. Similarly, transactional leadership trait increased the odds of nurses' job satisfaction by 1.110 , Wald $\chi^{2}(1)=1.17, p=0.280, \operatorname{Exp}(B)=1.110$ ), the observation being insignificant.

\section{Job stress and job satisfaction of nurses}

The study also sought to establish the extent to which perceived job stress predicted nurses' job satisfaction. Descriptively, reward had a greater impact on job satisfaction of nurses $(M=7.25, S D=2.82)$ compared to support at the work place $(M=6.96, S D=1.96)$ and workload $(\mathrm{M}=4.91, \mathrm{SD}=2.28)$. Table 6 show the results of an analysis of the impact based on logistic regression.

Table 6 Logistic regression results predicting nurses job satisfaction due to job stress

\begin{tabular}{lcccccc}
\hline & B & SE & Wald's $\boldsymbol{\chi}^{2}$ & df & Sig. & Exp(B) \\
\hline Workload & .264 & .095 & 7.718 & 1 & .005 & 1.302 \\
Support & .204 & .119 & 2.919 & 1 & .088 & 1.226 \\
Reward & .326 & .084 & 15.055 & & .000 & 1.385 \\
Constant & -6.330 & 1.338 & 22.368 & 1 & .000 & .002 \\
\hline
\end{tabular}

a. Variable(s) entered on step 1: Workload, Support, Reward

Workload, support and reward were the independent variables used in the model. The model was significant, $\chi^{2}(4)=26.08, p<0.001$ and the Hosmer and Lemeshow Test confirmed model fit, $\chi^{2}(8)=12.99, p=.112$. Cox \& Snell $\mathrm{R}$ Square predicted a variance of $19.6 \%$ while Nagelkerke R Square predicted $28.3 \%$ in variation in job satisfaction explained by the model. The model with independent variables explained $80.9 \%$ of nurses job satisfaction due to job stress, an improvement from the $72.3 \%$ initially predicted. Workload and reward significantly predicted nurses job satisfaction, Wald $\chi^{2}(1)=7.72, \mathrm{p}<0.01, \operatorname{Exp}(\mathrm{B})=1.302$; Wald $\chi^{2}(1)=$ $15.06, \mathrm{p}<0.01, \operatorname{Exp}(B)=1.385)$. Though insignificant, support increased the odds of nurses' job satisfaction by 1.226 .

\section{Work environment and nurses' job satisfaction}

The last objective sought to examine how nurses' work environment contributes to their job satisfaction. The contributions were examined through collaboration, personnel and work climate as sub-scales of work environment. Descriptive data indicated that the contribution of relationships towards job satisfaction $(\mathrm{M}=8.12, \mathrm{SD}=2.480)$ was higher compared to equipment $(M=4.79, S D=1.856)$ and personnel $(M=4.57, S D=1.973)$. Logistic regression used to illustrate the subscales that best predict job satisfaction of the nurses returned findings as indicated in Table 7. 
Table 7 Logistic regression results predicting nurses job satisfaction due to work environment

\begin{tabular}{lcccccc}
\hline & B & SE & Wald's $\chi^{2}$ & df & Sig. & Exp(B) \\
\hline Relationship & .251 & .116 & 4.666 & 1 & .031 & 1.285 \\
Personnel & .341 & .140 & 5.965 & 1 & .015 & 1.407 \\
Equipment & .073 & .158 & .210 & 1 & .647 & 1.075 \\
Constant & -5.122 & .932 & 30.229 & 1 & .000 & .006 \\
\hline
\end{tabular}

a. Variable(s) entered on step 1: Relationships, Personnel, Equipment.

Relationships, personnel and equipment were similarly used as independent variables. The model was significant, $\chi^{2}(1)=25.18, p<0.001$ and the Hosmer and Lemeshow Test confirmed model fit, $\chi^{2}(8)=2.50, p=0.962$. Cox \& Snell R Square predicted a variance of $21.6 \%$ while Nagelkerke R Square predicted $31.1 \%$ in variation in nurses' job satisfaction explained by the model. The model with independent variables explained $79.6 \%$ of nurses' job satisfaction due to work environment, an improvement from the $71.8 \%$ initially predicted. Relationships and personnel significantly predicted job satisfaction of nurses, Wald $\chi^{2}(1)=4.67, p=0.031, \operatorname{Exp}(B)$ $=1.285$; Wald $\left.\chi^{2}(1)=5.97, \mathrm{p}=0.015, \operatorname{Exp}(\mathrm{B})=1.407\right)$. Though insignificant, equipment increased the odds of job satisfaction by 1.075 .

\section{Discussion}

\section{DISCUSSIONS AND CONCLUSION}

The study intended to establish factors influencing job satisfaction of nurses in public hospitals in Kenya with specific focus on nurses in public hospitals in Mombasa, Kwale and Kilifi counties. Specifically the study sought to explore the existing relationship between demographic factors such as age, gender, marital status and education on job satisfaction of nurses; establish the extent to which perceived leader empowering behaviours contributes to job satisfaction of nurses and examine the impact job stress has on job satisfaction of nurses. Further it sought to examine how work environment contributes to the job satisfaction of nurses. Data was obtained through structured questionnaire to the respondents. Findings are discussed as per the objectives.

For the first objective, findings established that more of the nurses were females compared to males. This is explained by the fact that care of the sick has predominantly been perceived to be a feminine role in most societies. Consequently, more females than males have taken up the challenge to offer care to the sick as nurses thus the higher population. The finding is consistent with previous studies such as Milutinovic' et al. (2012) and Welsh (2009) whose studies established a $78.7 \%$ female ratio compared to $21.3 \%$ for male among nurses involved in their study. In Ghana, a study undertaken by Sanda and Cudjoe (2018) observed 83.7\% female to $16.3 \%$ male nurse ratio. With regard to job satisfaction, only age was found to significantly influence nurses' job satisfaction $(\mathrm{p}=0.049)$. Younger nurses reported being highly satisfied compared to the older ones. Gender, marital status, level of education and employment status of the nurses each had insignificant influence on their job satisfaction. The finding supports Tapia, Ramírez and Islas (2009) who established a decrease in JS with increase in age. However, it contradicts Curtis and Glacken (2014) as well as Li and Lambert (2008) who in their study findings established that job satisfaction of nurse's increases with increase in age. Similarly, Bhandari et al. (2015), García et al. (2010) and Ruzafa et al. (2008) reported no relationship between nurse age and job satisfaction.

The study also intended to establish the extent to which perceived leader empowering behaviour contributes to job satisfaction of nurses. Respondents scored highly for 
transformational leadership compared to transactional leadership. Logistic regression indicated that even though the odds of nurses' job satisfaction increased with both transformational and transactional leadership, the observation was insignificant at 0.05 level of significance. This implies that according to the sampled nurses, neither transformational nor transactional leadership traits of their nurse manager influences their job satisfaction. It is an indictment of the quality of leadership of the nurse managers in the hospitals since leadership is supposed to influence the led. The finding contradicts those of Casida \& Parker 2011, Abdelhafiz et al. (2015) and Morsiani et al. (2016).

Data obtained with regard to the impact of job stress on job satisfaction of nurses illustrated that respondents scored highly for reward compared to support and work load implying that descriptively, job satisfaction is influenced more by reward followed by support and lastly work load. Logistic regression indicated that a unit increase in work, support and reward increases the odd of nurse job satisfaction by 1.302, 1.226 and 1.385 respectively, the observation being significant for reward and work load respectively. This means that whereas work load, support and reward positively influences nurse job satisfaction, the influence due to work load and reward are significant. It implies that with regard to job stress, work load and reward are factors that influence nurses' job satisfaction. Previously, Doef et al., (2012) in their study of female nurses in Kenya, Tanzania and Uganda found that job stress negatively affected their job satisfaction. Makola et al. (2015) as well as Shihundla et al. (2016) reported that workloads, long working hours and unsatisfactory compensation were key drivers of job stress in Africa especially among nurses. Similarly, Seitovirta et al. (2016); Hsu et al. (2015) and Rowland and Hall (2014) pointed out reward to be a strong predictor of job satisfaction and inadequacy or lack of it. It was found to cause dissatisfaction and negatively affected nurses' performance.

Lastly, the study established that relationship contributes highly towards job satisfaction of nurses compared to equipment and personnel. Logistic regression indicated that a unit increase in relationship, personnel and equipment increases the odd of nurse job satisfaction by $1.285,1.407$ and 1.075 respectively, the observation being significant for relationship and personnel respectively. This means that according to the nurses, nurse physician relationship and personnel are factors that influence their job satisfaction. Studies undertaken in SSA showed that nurses perceived their working conditions as poor (Doef et al., 2012). Unfavourable personnel, increased workload, poor interdepartmental cooperation and equipment's and low financial reward were found to be contributing elements of poor working environment in East Africa (Doef et al., 2012). In Kenya, previous studies have documented increased number of HIV /AIDS patients, lack of resources in the hospitals and poor communication between hospital staff as key factors in contributing to poor levels of working environment (Raviola, Machoki, Mwaikambo \& Delvecchio, 2002). Studies carried out in developed countries found reported that positive perceptions of the work environment enhanced nurses' job satisfaction (Ganz \& Toren, 2014; Zhang et al., 2014; Rochefort \& Clarke, 2010). Doef et al. (2012) also acknowledged that job satisfaction is correlated with improved working conditions such as personnel, workload and availability of equipment. At the same time, inadequate nurse staffing has been considered as a key component of poor supportive work environment ( $\mathrm{Lu}$ et al., 2015), which is associated with higher job dissatisfaction (Nantsupawat et al., 2015).

\section{Conclusion}

The study established that nurses' age, time, work load and reward significantly influences their job satisfaction. Other factors found to significantly influence nurses' job satisfaction include nurse physician relationship and personnel were factors under work environment. 
Whereas it is advisable that efforts seeking to improve nurses' job satisfaction should focus on minimising job stress and improving work environment, it is also recommended that concerted efforts be put on improving the quality of leadership to inspire the nurses and thus enhance their job satisfaction, an aspect that was found missing.

\section{LIMITATIONS AND SUGGESTED FURTHER RESEARCH}

The study has a number of limitations. Data was collected in public hospitals in only three (3) out of the forty-seven (47) devolved units within the country that limits its generalizability. Secondly, data obtained was based on self-report measures. Future studies could build on these. Longitudinal studies are particularly more appropriate since they may be helpful in tracking changes in perception of nurses with regard to their jobs and related issues. It should also be noted that the findings of the present study have to be interpreted in a careful way since a convenience sampling procedure was applied. Respondents were drawn from public hospitals at County Hospitals and referral level only which could have caused uncontrolled bias.

\section{Reference}

Abdulla, J., Djebarni, R., \& Mellahi, K. (2010). Determinants of job satisfaction in UAE. A case study of the Dubai police. Personnel Review, 40 (1), 126-146.

Abualrub, R. F, \& Alghamdimg M. G (2012). The impact of leadership styles on nurses_satisfaction and intention to stay among Saudi nurses. Journal of Nursing Management. 20: 668-678.

Abuya, T., Maina, T., \& Chuma, J. (2015). Historical account of the national health insurance formulation in Kenya: experiences from the past decade. BMC Health Service Research. 15:56. doi.org/10.1186/s12913-015-0692-8.

Adriaenssens, J., De Gucht, V., van der Doef, M., \& Maes, S. (2011). Exploring the burden of emergency care: Predictors of stress-health outcomes in emergency nurses. Journal of Advanced Nursing, 67(6), 1317-1328

Al-Enezi, N., Chowdhury, R. I., Shah, M. A., \& Al-Otabi, M. (2009). Job satisfaction of nurses with multicultural backgrounds: a questionnaire survey in Kuwait. Applied Nursing Research, 22(2), 94-100.

Asegid, A., Belachew, T., \& Yimam, E., (2014). Factors influencing job satisfaction and anticipated turnover among nurses in Sidama zone public health facilities, South Ethiopia. Nursing Research and Practice 1-26.

Atefi, N., Abdullah, K.L.,Wong, L.P. \& Mazlom, R. (2013) Factors influencing job satisfaction among registered nurses: a questionnaire survey in Mashhad, Iran. Journal of Nursing Management. doi: 10.1111/ jonm.12151.

Brunetto Y., Xerri M., Farr-Wharton B., Shacklock K., Farrwharton R. \& Trinchero E. (2016) Nurse Safety outcomes: old problem, new solution - the differentiating roles of nurses' psychological capital and managerial support. Journal of Advanced Nursing 72(11), 2794-2805. doi: 10.1111/jan.13036

Chan, Z. C., Tam, W. S., Lung, M. K., Wong, W. Y., \& Chau, C. W. (2013). A systematic literature review of nurse shortage and the intention to leave. Journal of Nursing Management, 21(4), 605-613. doi:10.1111/j.13652834.2012.01437.

Clark, A. (2013), Job Satisfaction and Gender: Why Are Women So Happy at Work, Discussion Paper 4, ESRC Research Centre on Micro-social Change, University of Essex, London.

Curtis, E. A., \& Glacken, M. (2014). Job satisfaction among public health nurses: a national survey. Journal of Nursing Management, 22(5), 653-663.

Danish R. Q. \& Usman A. (2010) Impact of reward and recognition on job satisfaction and motivation: an empirical study from Pakistan. International Journal of Business and Management 5 (2), 159-167.

Day, A., Crown, S. N., \& Ivany, M. (2017). Organisational change and employee burnout: The moderating effects of support and job control. Safety science 100, 4-12.

Deriba, B. K., Sinke,S. O., Ereso, B. M., \& Badacho, A. S. (2017). Health professionals' job satisfaction and associated factors at public health centers in West Ethiopia. Human Resources for Health, 15:36

Dobre, I., Anamaria, A, D., \& Eid, M.T. (2017). Key factors of health employee motivation in Jordan. Evidence from dual-factor theory based on structural equation models. Economic Computation and Economic Cybernetics Studies and Research. 2, 51. 
Tengah, S. A., \& Otieno, O. J. (2019). Factors Influencing Job Satisfaction among Nurses in Public Health Facilities in Mombasa, Kwale and Kilifi Counties, Kenva. Advances in Social Sciences Research Journal, 6(5) 128-144.

Doef, M., Mbaazi, F., \& Verhoeven, C. (2012). Job conditions, job satisfaction, somatic complains and burnout among East African nurses. Journal of Clinical Nursing. 21: 1763-1775. doi.org/10.1111/j.1365-2702.2011.03995.

Dugguh, S, I., \& Dennis, A. (2014). Job satisfaction theories: Traceability to employee performance in organization. Journal of Business and Management 16 (5), 11-18.

Dugguh, S., \& Dennis, A. (2014). Job satisfaction theories: Traceability to employee performance in organizations. IOSR Journal of Business and Management, 16(5), 11-18.

Edmondson, D. R. \& Boyer, S.T. (2013). The Moderating Effect of the Boundary Spanning Role on Perceived Supervisory Support: A Meta-Analytic Review Journal of Business Research. 66, 112186 - 2192.

Elsetouhi, A. M., Hammad, A.A., Nagm, A. A., \& Elbaz, A. M. (2017). Perceived leader behavioural integrity and employee voice in SMEs travel agents: The mediating role of empowering leader behaviors. Tourism Management. $65,100-115$.

Freer, J., (2017). Sustainable development goals and the human resources crisis, International Health, 9, 1, 11-2.

Galletta, M., Portoghese, I., Penna, M. P., Battistelli, A., \& Saiani, L. (2011). Turnover intention among italian nurses: The moderating roles of supervisor support and organizational support. Nursing \& Health Sciences, 13, $184-191$.

García A, Moro M. N, \& Medina M (2010). Evaluation and dimensions that define the climate and job satisfaction in the nursing staff. Rev Calid Asist. 25 (4): 207-14.

García, C. C., Solano-Ruíz , M. C., Martínez-Roche, M. E. \& Gómez-García , C. I. (2013). Influence of gender and age: job satisfaction of health professionals. Latin American Journal of Nursing, 12, 6

Gilson, L. (2009). Developing a tool to measure health worker motivation in district hospitals in Kenya. Human Resource Health. 7, 40-51.

Hagopian, A., Zuyderduin, A., Kyobutungi, N., \& Yumkella, F. (2009). Job satisfaction and morale in the Ugandan health workforce. Health Affairs 28, 863-875.

Hamdan-Mansour AM, Al-Gamal E, Puskar K, Yacoub M, \& Marini A. (2011). Mental health nursing in Jordan: an investigation into experience, work stress, and organizational support. Int J Ment Health Nurs. 20(2):86-94.

Happell B, Dwyer T, Reid-Searl K, Burke K, Caperchione C, \& Gaskin C. (2013). Nurses and stress: recognizing causes and seeking solutions. J Nurs Manag. 21:638-647.

Hayes L, O"Brien-Pallas L, Duffield C, et al. (2012). Nurse turnover: a literature review Van update. Int J Nurs Stud. 49: 887-905.

Herrera G, Manrique FG. Working conditions and degree of satisfaction of nursing professionals. Aquichan. 2008; 8 (2): 243-56.

Holmberg, C., Caro, J., \& Sobis, I. (2018). Job satisfaction among Swedish mental health nursing personnel: Revisiting the two-factor theory. International Journal of Mental Health Nursing 27, 581-592.

Hsu, C. P., Chiang, C. Y., Chang, C. W., Huang, H. C., \& Chen, C. C. (2015). Enhancing the commitment of nurses to the organisation by means of trust and monetary reward. Journal of Nursing Management, 23(5), 567-576.

Islam R. \& Ismail A.Z.H. (2008) Employee motivation: a Malaysian perspective. International Journal of Commerce and Management 18 (4), 344-362.

Jones, T. L. (2011). Effects of motivating and hygiene factors on job satisfaction among school nurses. PhD thesis, Walden University, Minneapolis, MN.

Kalisch BJ, Lee H, Rochman M. Nursing staff teamwork and job satisfaction. J Nurs Manag [Internet]. 2010;18:93847. Available from: http://onlinelibrary. wiley.com/doi/:10.1111/j.1365-2834.2010.01153.x/full

Khamisa, N., Peltzer, K., Ilic, D., \& Oldenburg, B. (2016). Work related stress, burnout, job satisfaction and general health of nurses: A follow-up study. International Journal Nurses Practice 22: 538-545.

Kimanthi, K. \& Nyamai, F. (2017, November 2). Kenyan nurses end their 5-month after deal with state. Daily Nation. Retrieved from https://www.nation.co.ke/news/Kenyan-nurses-end-4-month-strike-after-deal-withState/1056-4166940-mo35skz/index.html

Klopper H.C., Coetzee S.K., Pretorius R. \& Bester P. (2012) Practice environment, job satisfaction and burnout of critical care nurses in South Africa. Journal of Nursing Management 20 (5), 685-695.

Kumar R. Job satisfaction among public health professionals working in public sector: a cross sectional study from Pakistan. Hum Res Health. 1478-4491-11-2. 
Li , J., and Lambert, V. A. (2008).Workplace stressors, coping, demographics and job satisfaction in Chinese intensive care nurses. Nursing in Critical Care. 13,1

Lim J, Bogossian F, \& Ahern K (2010). Stress and coping in Australian nurses: a systematic review. Int Nurs Rev. 57: 22-31.

Lin, H. S., Probst, J. C., \& Hsu, Y. C. (2010). Depression among female psychiatric nurses in southern Taiwan: main and moderating effects of job stress, coping behaviour and social support. J Clin Nurs. 19(15-16):2342-2354.

Lindqvist, R., Alenius, L.S., Runesdotter, S., Ensio, A., Jylhä, V., Kinnunen, J., Sjetne, I.S., Tvedt, C., Tjønnfjord, M. W., \& Tishelman, C. (2014). Organization of nursing care in three Nordic countries: relationships between nurses' workload, level of involvement in direct patient care, job satisfaction, and intention to leave. BMC Nursing, 13 - 27.

Lu, H., Barriball, K. L., Zhang, X. \& While, A. E. (2012). Job satisfaction among hospital nurses revisited: A systematic review. International Journal of Nursing Studies, 49, 10-17.

Malliarou, M., Sarafis, P., Moustaka, E., Kouvela, T., \& Constantinidis, T. C. (2010). Greek Registered Nurses' Job Satisfaction in Relation to Work-Related Stress. A Study on Army and Civilian Rns. Global Journal of Health Science. 2,1 .

McGlynn, K., Griffin, M. Q., Donahue, M., \& Fitzpatrick, J. J. (2012). Registered nurse job satisfaction and satisfaction with the professional practice model. Journal of Nursing Management, 20, 260-265. doi:10.1111/j.13652834.2011.01351.x

Mendenhall, E., Isaiah, G., Nelson, B., Musau, A., Koon, A. D., Smith, L., Mutiso, V., \& Ndetei, D. (2018) Nurses' perceptions of mental healthcare in primary-care settings in Kenya, Global Public Health, 13:4, 442455, doi: 10.1080/17441692.2016.1207196.x

Mera, M. J. F, Vinagre Gaspar R, Zaragoza García I, Viñas Sánchez S, Antúnez Melero E, Álvarez González S, et al. (2009). Síndrome de burnout en distintas Unidades de Cuidados Intensivos. Enferm Intensiva. 20(4):131-40.

Milutinovic, D., Golubovic, B., Brkic, N., Prokeš, B. (2012). Professional stress and health among critical care nurses in Serbia. Archives of Industrial Hygiene and Toxicology. 63: 171-180.

Morsiani, G., Bagnasco, A., \& Sasso, L. (2016). How staff nurses perceive the impact of nurse managers leadership style in terms of job satisfaction: a mixed method study. Journal of Nursing Management. 25, 2.

Ng, T. W. H., \& Sorensen, K. L. (2008). Toward a further understanding of the relationships between perceptions of support and work attitudes: A meta-analysis. Group \& Organization Management, 33, 243-268.

Okeyo, V. (2017, August 14). Despite all efforts to resuscitate Kenya's public healthcare, patients still cannot access quality primary care. Daily Nation, Retrieved from https://www.nation.co.ke/health/Healthcareindications-at-a-glance/3476990-4057102-7enuw7z/index.html

Onsarigo. D. (2014, August 14). Kenya: Striking nurses list their grievances. The Star. Retrieved fromhttp://allafrica.com.liverpool.idm.oclc.org/stories/201408140816.html

Pillay, R. (2008). Work satisfaction of professional nurses in South Africa: a comparative analysis of the public and private sectors. Human Resources for Health, 7: 7-15.

Preiss, A., \& Molina-Ray, C. (2007). Leadership training for Managers. Journal of Leadership Studies. 1 (1), 8.

Ramírez M, Lee SL.(2011). Burnout syndrome between men and women measured by climate and job satisfaction. Polis, Rev Univ Bolivariana. 10 (30): 431-46.

Ruzafa M, Madrigal M, Velandrino A, \& López L. (2008) Job satisfaction of Spanish nursing professionals working in English hospitals. Gac Sanit. 22 (5): 434-42.

Sanda , M. A. \& Cudjoe, E. (2018) Identification of Factors Predictive of Nurses' Time Pressure, Workload and Job Satisfaction in Ghanaian Public Hospitals. Advances in Human Factors, Business Managementand Leadership, Advances in Intelligent. 594

Schalkwyk, S.V., Du Toit, D.H., Bothma, A.S., \& Rothmann, S. (2010). Job insecurity, leadership empowerment behavior, employee engagement and intention to leave in a petrochemical laboratory. SA Journal of Human Resource Management. 8 (1), 1-7.

Seitovirta, J., Lehtimäki, A.-V, Vehviläinen-Julkunen, K., Mitronen, L., \& Kvist, T. (2017). Development and psychometric testing of the Registered Nurses' Perceptions of Rewarding Scale. Journal of Nursing Research, in press. 
Tengah, S. A., \& Otieno, O. J. (2019). Factors Influencing Job Satisfaction among Nurses in Public Health Facilities in Mombasa, Kwale and Kilifi Counties, Kenva. Advances in Social Sciences Research Journal, 6(5) 128-144.

Semachew, A., Belachew, T.,, Tesfaye, T., \& Adinew, Y. M. (2017). Predictors of job satisfaction among nurses working in Ethiopian public hospitals, 2014: institution-based cross-sectional study. Human Resources for Health. $15: 31$

Sharma, D. B., Shah, U. M., Patel, R., Gupta, V., \& Singh, U. S. (2018). Determinants of job satisfaction amongst medical officers of primary health centre in Anand district, Gujarat, India

Sharp, T.P. (2008). Job satisfaction among psychiatric registered nurses in New England. Journal of Psychiatric and Mental Health Nursing, 15(5), 374-378.

Shihundla, R. C., Lebese, R. T., \& Maputle, M. S. (2016). Effects of increased nurse's workload on quality documentation of patient information at selected Primary Health Care facilities in Vhembe District, Limpopo Province. Curationis. 39: 1545.

Simatwa, E. M. W. (2011). Job Satisfaction and Dissatisfaction among Teachers in Kenya. Kenya Journal of Education Planning Economics and Management, 3 (3), 114-123.

Smollan, R.K., 2015. Causes of stress before, during and after organizational change: a qualitative study. J. Organ. Change Manage. 28 (2), 301-314.

Stello, C. M. (2011). Herzberg's Two-Factor Theory of Job Satisfaction: An Intergrative Literature Review. Minnesota: Department of Organisational Leadership, Policy and Development.

Stephen I. D., \& Ayaga, D. (2014). Job satisfaction theories: Traceability to employee performance in organizations. Journal of Business and Management, 16, 1, 11-18.

Tapia H, Ramírez C, Islas E. (2009). Work satisfaction in nurses of the oncology hospital National Medical Center Siglo XXI IMSS. Rev Enferm Universit ENEO-UNAM. 6: 21-5.

Tarcan, M., Hikmet, N., Schooley, B., Top, M., and Tarcan, G. Y. (2017). An analysis of the relationship between burnout, socio-demographic and workplace factors and job satisfaction among emergency department health professionals. Applied Nursing Research, 34, 40-47.

Top. M., Tarcan, M., Tekingündüz, S., \& Hikmet N. (2013). An analysis of relationships among transformational leadership, job satisfaction, organizational commitment and organizational trust in two Turkish hospitals. International Journal Health Planning Thoits, P.A. (2010). Stress and health: major findings and policy implications. Journal of Health and Social Behaviour, 51, 41-53

Utrianen, K. and Kyngas, H. (2009). Hospital nurses' job satisfaction: a literature review. Journal of Nursing Management, 17, 8.

Viswam, A., Valsaraj, B. P \& Jose, T. T (2013). A comparative study to assess job satisfaction among married staff nurses and nursing faculty in selected institutions of Udupi and Mangalore Taluks. I-manager's Journal on Nursing, 3,3 .

Von Bonsdorff, M. E. (2011). Age-related differences in reward preferences. The International Journal of Human Resource Management, 22(6), 1262-1276.

Wahito, M. (2013, December 21). Nurses Grumble after Deal to End Strike. Capital News, Retrieved https://www.capitalfm.co.ke/news/2013/12/nurses-grumble-after-deal-to-end-strike/

Xanthopoulou, D., Bakker, A. B., Demerouti, E., \& Schaufeli, W. B. (2009). Reciprocal relationships between job resources, personal resources, and work engagement. Journal of Vocational Behavior, 74, 235-244. 